\title{
Relationship power, communication, and violence among couples: results of a cluster-randomized HIV prevention study in a South African township
}

This article was published in the following Dove Press journal:

International Journal of Women's Health

II May 2015

Number of times this article has been viewed

\author{
Alexandra M Minnis ${ }^{1,2}$ \\ Irene A Doherty 1,3 \\ Tracy L Kline' \\ William A Zule' \\ Bronwyn Myers ${ }^{4,5}$ \\ Tara Carney ${ }^{4}$ \\ Wendee MWechsberg ${ }^{1,3,6,7}$ \\ 'RTI International, Research Triangle \\ Park, NC, ${ }^{2}$ School of Public Health, \\ University of California, Berkeley, CA, \\ ${ }^{3}$ University of North Carolina, Chapel \\ Hill, NC, USA; ${ }^{4}$ Alcohol, Tobacco and \\ Other Drug Research Unit, South \\ African Medical Research Council, \\ ${ }^{5}$ Department of Psychiatry and Mental \\ Health, University of Cape Town, \\ Cape Town, South Africa; ${ }^{6}$ North \\ Carolina State University, Raleigh, \\ ${ }^{7}$ Duke University School of Medicine, \\ Durham, NC, USA
}

Background: Inequitable gender-based power in relationships and intimate partner violence contribute to persistently high rates of HIV infection among South African women. We examined the effects of two group-based HIV prevention interventions that engaged men and their female partners together in a couples intervention (Couples Health $\mathrm{CoOp}[\mathrm{CHC}]$ ) and a gender-separate intervention (Men's Health CoOp/Women's Health CoOp [MHC/WHC]) on women's reports of power, communication, and conflict in relationships.

Methods: The cluster-randomized field experiment included heterosexual couples from a high-density South African township in which neighborhoods were randomized to one of the intervention arms or a control arm that received the WHC only. Participants completed in-person study visits at baseline and 6-month follow-up. We examined group differences using one-way analysis of variance and multivariable regression models.

Results: Of the 290 couples enrolled, 255 women remained in the same partnership over 6 months. Following the intervention, women in the CHC arm compared with those in the WHC arm were more likely to report an increase in relationship control ( $\beta=0.92,95 \%$ confidence interval $[\mathrm{CI}]: 0.02,1.83, P=0.045)$ and gender norms supporting female autonomy in relationships ( $\beta=0.99,95 \% \mathrm{CI}: 0.07,1.91, P=0.035$ ). Women in the MHC/WHC arm were more likely to report increases in relationship equity, relative to those in the $\mathrm{CHC}$ arm, and had a higher odds of reporting no victimization during the previous 3 months (MHC/WHC vs WHC: odds ratio $=3.05,95 \% \mathrm{CI}: 1.55,6.0, P=0.001 ; \mathrm{CHC}$ vs $\mathrm{MHC} / \mathrm{WHC}$ : odds ratio $=0.38$, 95\% CI: $0.20,0.74, P=0.004)$.

Conclusion: Male partner engagement in either the gender-separate or couples-based interventions led to modest improvements in gender power, adoption of more egalitarian gender norms, and reductions in relationship conflict for females. The aspects of relationship power that improved, however, varied between the couples and gender-separate conditions, highlighting the need for further attention to development of both gender-separate and couples interventions.

Keywords: gender, partner interventions, empowerment, HIV prevention

\section{Introduction}

Inequitable gender-based power in relationships and intimate partner violence (IPV) are known to contribute to the persistently high rates of HIV infection among South African women. ${ }^{1}$ Despite important legal and policy efforts adopted to achieve greater gender equality in South Africa (eg, Commission for Gender Equality), patriarchal norms remain deeply entrenched. Indeed, gender norms and strategies adopted to express masculinity are shaped by historical disempowerment and the legacies of colonization and apartheid, which restricted opportunities to achieve traditional milestones of adulthood. ${ }^{2}$ There are multiple pathways whereby gender
Correspondence: Alexandra M Minnis Women's Global Health Imperative, RTI International, 35 I California Street, Suite 500, San Francisco, CA 94104, USA

Tel +l 4I5848 I323

Email aminnis@rti.org 
power imbalances and IPV increase HIV risk for women: low control over sexual decision making in relationships, including decreased ability to negotiate condom use and inform decisions about when to have sex; acceptance of men having multiple sexual partners; and little sexual and relationship communication among partners. ${ }^{3,4}$ Alcohol and other drug use may exacerbate the effect of gender power imbalances and IPV on HIV risk. ${ }^{5,6}$

Several HIV prevention interventions in sub-Saharan Africa have directly addressed gender inequities, relationship communication, and IPV. ${ }^{7-9}$ Structural interventions that aim to change the contextual environments in which young women make partnership and HIV prevention decisions have demonstrated some success in reducing IPV and HIV risk. Providing group-based microfinance alongside gender and HIV training, for example, led to a significant reduction in IPV as well as improvements across multiple measures of empowerment among young, rural women in South Africa. ${ }^{7}$ Similarly, conditional cash transfer interventions that promote schooling for girls have demonstrated promise as an HIV prevention strategy. ${ }^{10}$ Whether this approach also addresses gender inequalities, which may be influential in achieving sustained improvements in HIV risk, requires further inquiry. ${ }^{11}$

While these interventions have focused on changing the broader risk environment for women, they have not included male partners directly within the intervention. The risk behaviors of male partners, however, constitute an important component of women's HIV risk environment, and there is increased recognition of the importance of promoting male engagement in HIV prevention interventions that target women directly. ${ }^{12}$ Evidence from trials of biomedical prevention, such as microbicides and oral preexposure prophylaxis, points to the influential roles that men assume in women's decision making, autonomy, and prevention choices. ${ }^{13,14}$ In an HIV prevention trial of the diaphragm, women who reported experiencing IPV reported lower levels of condom and diaphragm use. ${ }^{15}$ Further, there is some emerging evidence that directly engaging men in HIV prevention interventions can lead to improved relationship outcomes, improved sexual decision making, and reduced relationship conflict. ${ }^{16,17}$ In addition, engaging couples together in couples-based HIV testing and counseling or in prevention interventions has proven more effective for reducing women's HIV incidence than intervening with female partners only. ${ }^{18,19}$ Despite this emerging evidence of the benefits of engaging men alongside their female partners in IPV and HIV prevention interventions, little is known about the effects of engaging men in group-based interventions on women's perceptions of gender power, gender norms, and relationship communication in their primary partnerships and on IPV. ${ }^{3}$

This paper begins to address this gap by examining the effects of two group-based HIV prevention intervention approaches that engaged men as participants alongside their female partners on relationship power, communication, and relationship conflict 6 months after enrollment. In the first intervention model, group-based sessions were held with men and women separately (gender separate), and in the second, men were engaged in the intervention together with their female partners (couples intervention). We compared outcomes among the female members of the couple residing in neighborhoods randomized to each intervention arm to those residing in neighborhoods randomized to a control arm that received an evidence-based women-only group intervention, the Women's Health CoOp (WHC). ${ }^{20}$

\section{Methods \\ Study design and population}

This cluster-randomized field experiment engaged the male/ female dyad either within a couples intervention or within a gender-separate intervention, both designed to reduce HIV incidence and risk behaviors. Improvements in gender equity and communication within the relationship as well as reductions in intimate partner conflict and violence constituted primary conceptual mechanisms through which HIV risk reductions were anticipated to be achieved. We recruited heterosexual couples from neighborhoods in Khayelitsha, a large high-density township with high HIV prevalence in the Western Cape Province, South Africa, from June 2010 through April 2012. Study methods have been described in detail elsewhere. ${ }^{21}$ Briefly, neighborhoods were randomized to one of three arms, which included 1) a standard care arm where women received the WHC intervention and men received HIV testing and counseling (referred to as WHC), 2) a gender-separate condition with the WHC intervention delivered to women and the Men's Health CoOp (MHC) delivered to men (referred to as $\mathrm{MHC} / \mathrm{WHC}$ ), and 3) the Couples Health CoOp intervention whereby couples received intervention content jointly (referred to as $\mathrm{CHC}$ ).

Study recruitment employed community-based outreach with men in drinking establishments (shebeens) within each neighborhood. Eligibility criteria for males included the following: 18-35 years of age, Black African, lived in Khayelitsha, reported drinking alcohol and frequenting shebeens at least weekly in the past 90 days, and reported unprotected sex. Male and female participants were 
screened separately. Both partners had to independently report being in the relationship for at least 12 months, planning to stay together for at least another year, and not intending to become pregnant in the next year. Each partner individually completed a study interview and biological testing for HIV, alcohol, and other drugs. After receiving the intervention to which they had been assigned, participants completed a 6-month follow-up visit in which the baseline biobehavioral assessment was re-administered. The Institutional Review Boards at RTI International and at Stellenbosch University's Faculty of Health Sciences granted ethical approval for the study.

\section{Intervention conditions}

Each intervention consisted of two, 3-hour sessions delivered 1 week apart by peer leaders within the community. Each session comprised two modules (four modules total). All three intervention arms addressed the following: alcohol and other drug use, harm reduction, and treatment; sexually transmitted infections (STIs), HIV, safer sex methods, and pleasuring each other; gender roles and gendered expectations about sex; effective communication and conflict resolution skills; dealing with stress; and violence prevention.

\section{WHC intervention}

Two of the arms utilized the WHC intervention. The WHC, an evidenced-based behavioral intervention, has been described elsewhere. ${ }^{20,22}$ The original Women's CoOp, a women-focused intervention consisting of two sessions designed to decrease substance use and sexual risk, was developed in the US in North Carolina with African-American women who used drugs. ${ }^{23}$ Its seven core elements, which are based in feminist and empowerment theories, include 1) educational cue cards that address risk-reduction information for substance use and HIV/STIs, 2) peer interventionists who receive extensive training, 3 ) behavioral skills training for sexual protection, 4) role plays of how to negotiate for safer sex and how to communicate, 5) individualized action plans to set goals and strategies for behavior change, 6) HIV testing, and 7) referral to necessary agencies. ${ }^{24}$ The core elements of the original intervention have been adapted for a variety of settings, including for South Africa, where additional content on violence and victimization was included. Session 1 provided participants with information about drug use and risks (module 1) and how sex behaviors can increase HIV risk. This session also taught sexual negotiation skills and correct condom use (module 2). Session 2 focused on relationship power, communication, and negotiation skills with male partners (module 3 ) and addressed violence against women and strategies for avoiding potentially violent situations (module 4). At the end of the second session, participants completed personalized, risk-reduction action plans that built on key messages that shaped the intervention content and approach.

The WHC was only slightly modified for this project to include more visuals and to incorporate focus group participants' voices within the body of the intervention to ensure cultural and gender congruence. Additional information on risks associated with drinking venues, reproductive organs, traditional vs modern gender roles, and activities to improve communication skills were added.

\section{MHC intervention}

The MHC intervention paralleled the WHC's format and duration but also included elements from the Men as Partners (MAP) program, developed by Engender Health and the Planned Parenthood Association of South Africa. ${ }^{17}$ The original MAP curriculum ${ }^{25}$ was designed to engage men in reducing gender-based violence by challenging their attitudes, values, and behaviors and promoting positive sexual and reproductive health, including HIV prevention. Several concepts and activities related to gender roles were utilized in the MHC. Like in the WHC, men in the MHC intervention completed personalized action plans at the conclusion of session 2 .

\section{$\mathrm{CHC}$ intervention}

The CHC extends the WHC by integrating essential components from Project Connect, ${ }^{26}$ an efficacious couples-based HIV intervention. ${ }^{19,27}$ The $\mathrm{CHC}$ intervention specifically focused on communication strategies (eg, speaker-listener technique) and negotiation skills as well as the effect that traditional gender roles and expectations may have on keeping couples in conflict. Couples practiced exercises in dyads as well as with the larger intervention group (eg, discussions of why couples stay together and what constitutes "good" or "bad" sex). The CHC reinforced positive dimensions of couples' relationships and used a handbook that extended the sessions through take-home activities and a commitment pledge that couples were asked to complete together.

\section{Measures}

Relationship power, communication, and conflict, assessed through multiple, validated scales, constituted the primary outcomes for the analysis. We examined the internal consistency of the items comprising each scale and determined that 
for all scales included in the analysis, the Cronbach's alpha was greater than 0.75 , both at baseline and at follow-up $(>0.8$ for nearly all scales). We also examined the consistency of scale items to ensure that they functioned similarly at both time points. We calculated Rasch category response curves for items in scales with limited variability in response to statistically evaluate whether these items could be removed when calculating the scale score. For the scale assessing partner victimization, for example, this analysis indicated that several items could be removed.

\section{Relationship power}

Relationship power was evaluated through two subscales of the Sexual Relationship Power Scale, ${ }^{28}$ one measuring women's control in relationships and the other measuring relationship equity in decision making. The women's control in relationships scale assessed agreement with ten statements related to the main partner in the previous 3 months and included items such as "You influence your main partner's actions" and "You get your main partner to do things your way". Response categories were "agree", "disagree", and "unsure". The eight-item shared decision-making scale assessed items such as "who usually has more say about what you do together" and "who usually has more say about when you talk about serious things". Items also addressed sexual decision making, including when they have sex and what type of sex and whether condoms are used. For each item, participants were asked to indicate whether their main partner usually has more say, whether both partners have equal say, or whether the participant has more say. The reliability coefficient (Cronbach's alpha) for each one, respectively, at baseline was 0.74 and 0.84 .

\section{Relationship communication}

Relationship communication measures assessed whether discussions between partners regarding HIV prevention, condom negotiation, and sexual risk behaviors had taken place in the previous 6 months. Eleven modified items from Wingood and DiClemente 29 included questions such as "In the past six months did you ask your main partner to use a condom; refuse to have sex with your main partner without a condom; ask your main partner how many sex partners he/she has had; and ask that your main partner get tested for HIV." Response options were yes/no, and the reliability coefficient was 0.92 .

\section{Gender norms}

Gender norms were assessed through a ten-item Gender Ideology subscale of the Power and Attitudes in Relationships scale. ${ }^{30}$ This scale examines the power distribution between men and women in heterosexual relationships. Using a four-point Likert scale, participants were asked to state the extent to which they agreed with statements regarding gender roles, relative importance of male vs female opinions, relationship happiness, and sexual autonomy. Sample items include "A woman should confront her main partner if she finds out he has a lover" and "Women don't need to have sex as much as men do". Higher scores are associated with less traditional and subservient roles for women. The reliability coefficient at baseline was 0.83 .

\section{Conflict and violence}

Conflict and violence measures included a set of ten victimization questions that assessed different types of IPV, including verbal/emotional, intimidation, and physical violence. These measures compose a subset of the World Health Organization victimization scale. ${ }^{31}$ Treated as a count of the number of types of violence experienced in the previous 3 months, the reliability coefficient was 0.91 .

Descriptive relationship characteristics were assessed at baseline and follow-up and include marital status (married vs unmarried), length of relationship in years, whether the couple has children, relationship satisfaction (excellent, good, just okay/not good), and perceived levels of relationship control.

\section{Analysis}

This analysis includes female participants from all three study arms who completed their 6-month follow-up visit and reported being in partnership with the same man with whom they enrolled at baseline. The primary question was whether two group-based intervention models that engage couples (gender separate vs couples groups) affected dimensions of gender-based power relative to a women-only group intervention. Thus, we structured the analysis around three pairwise comparisons: $\mathrm{CHC}$ vs WHC, MHC/WHC vs WHC, and $\mathrm{CHC}$ vs MHC/WHC. We employed two analytic approaches: 1) one-way analysis of variance examining differences in mean changes in scores from baseline to follow-up for each intervention condition, followed by paired $t$-tests; and 2) linear regression to examine potential differences in scores between intervention conditions while adjusting for baseline levels. For non-normally distributed outcomes, we used nonparametric approaches to test for differences in medians, including Kruskal-Wallis tests for three-group comparisons and Wilcoxon rank-sum tests to examine pairwise differences between intervention arms. We checked model assumptions using standard procedures to test distributions for normality and for equality of variances across treatment groups. 
For multivariable analysis of partner victimization, we used logistic regression with a dichotomous outcome reflecting no vs any experience of recent victimization.

\section{Results}

\section{Background characteristics}

Two hundred and ninety women enrolled in the study with their male partner, with $95 \%$ retention at 6-month follow-up $(\mathrm{N}=275)$. As reported elsewhere, ${ }^{32}$ women had a mean age of 24.2 years (range 18-39 years). Nearly three-quarters (71.6\%) did not live with their main partner, and the majority of the rest lived together but were not married (Table 1). The median relationship length was 2.7 years (interquartile range 2-4 years). One-third (29.1\%) had children with their partner. Most women reported at baseline that their relationship was excellent $(50 \%)$ or good $(38 \%)$. Sixty-three percent stated that their partner was at least somewhat controlling in their relationship. Though nearly two-thirds $(63.5 \%)$ reported having had a conflict or argument with their partner in the previous 3 months, half of which were prompted by alcohol use, very few involved physical aggression (4\%), and most reported resolving these conflicts through discussion. Ninety-three percent of women who completed a follow-up visit $(\mathrm{N}=255)$ reported still having the same partner as they did at baseline.

\section{Relationship control}

At baseline, women reported a moderately high level of influence and control in relationships, with an overall mean of 7.36 ( standard deviation $=2.22$ ) across ten measures (Table 2). Changes in relationship power at 6 months were modest; only participants in the $\mathrm{CHC}$ intervention reported a positive change, reflecting a mean increase in women's perceived control in their relationship. In linear regression analysis examining intervention effects on changes in

Table I Baseline relationship characteristics of women, Western Cape Couples Health CoOp Study, Cape Town, South Africa, 2010-2012

\begin{tabular}{|c|c|c|}
\hline & \multicolumn{2}{|l|}{ Overall } \\
\hline & \multicolumn{2}{|l|}{$\mathbf{N}=\mathbf{2 7 5}^{\mathrm{a}}$} \\
\hline & $\mathbf{N}$ & $\%$ \\
\hline \multicolumn{3}{|l|}{ Relationship characteristics } \\
\hline \multicolumn{3}{|l|}{ Relationship status } \\
\hline Married & 8 & 2.9 \\
\hline Living together but not married & 70 & 25.5 \\
\hline Not living with main partner & 197 & 71.6 \\
\hline Relationship length (years): median (IQR) & $2.7(2-4)$ & \\
\hline Has children with partner & 80 & 29.1 \\
\hline \multicolumn{3}{|l|}{ Relationship satisfaction } \\
\hline Excellent & 137 & 50.0 \\
\hline Good & 104 & 38.0 \\
\hline Just okay/not very good & 33 & 12.0 \\
\hline \multicolumn{3}{|l|}{ Relationship control } \\
\hline \multicolumn{3}{|l|}{ Perceived level of partner control } \\
\hline Very controlling & 40 & 14.7 \\
\hline Somewhat/moderately controlling & 132 & 48.4 \\
\hline Not very/not at all controlling & 101 & 37.0 \\
\hline \multicolumn{3}{|l|}{ Beliefs regarding control over sexual decision makingb } \\
\hline A woman can refuse sex with her partner in all circumstances & 246 & 89.8 \\
\hline \multicolumn{3}{|l|}{ Relationship conflict } \\
\hline Conflict with main partner previous 3 months & 174 & 63.5 \\
\hline \multicolumn{3}{|l|}{ Primary causes of conflict/argument ${ }^{c}$} \\
\hline Drinking & 87 & 50.0 \\
\hline Flirting & 18 & 10.3 \\
\hline Cheating & 38 & 21.8 \\
\hline Money & 40 & 23.0 \\
\hline Insensitivity to emotional needs & 61 & 35.1 \\
\hline \multicolumn{3}{|l|}{ Actions involved in conflict ${ }^{c}$} \\
\hline Discussion/talking & 157 & 90.2 \\
\hline Screaming/yelling & 28 & 16.1 \\
\hline Crying & 10 & 5.7 \\
\hline Physical aggression & 7 & 4.0 \\
\hline
\end{tabular}

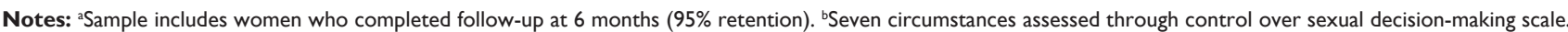
'Participants could choose more than one.

Abbreviation: IQR, interquartile range. 


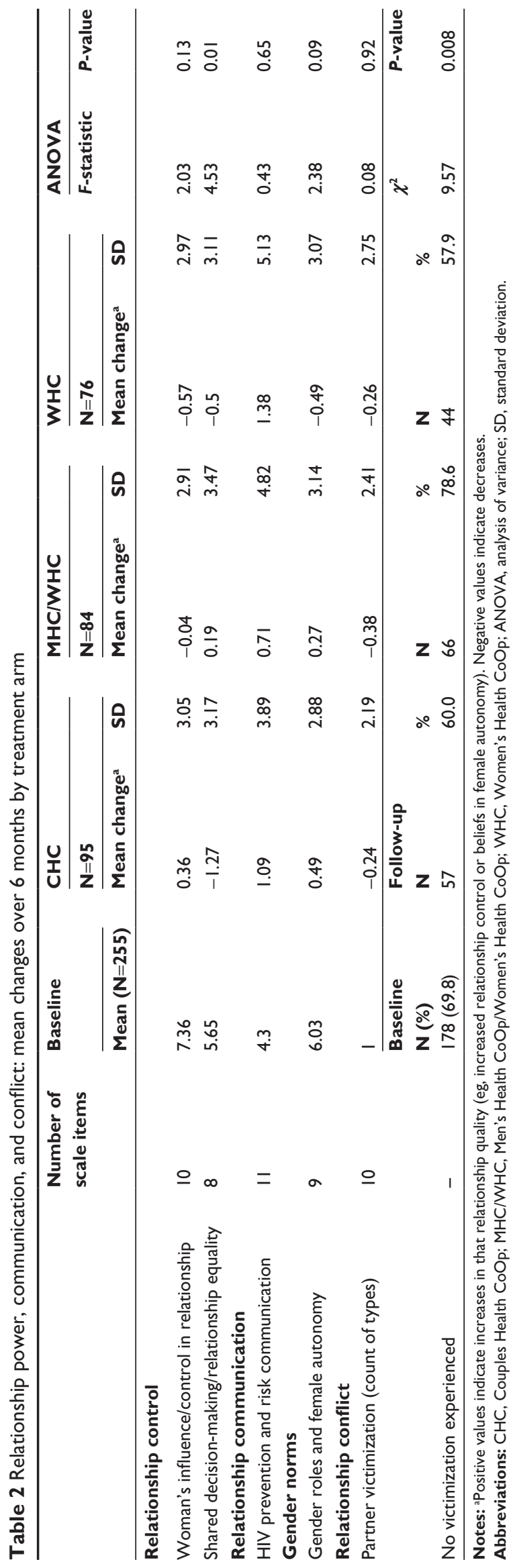

relationship control scores between baseline and follow-up (Table 3), women in the $\mathrm{CHC}$ arm compared with those in the WHC arm reported a positive increase in relationship control ( $\beta=0.92,95 \%$ confidence interval [CI]: 0.02, 1.83, $P=0.045$ ). For the second measure of relationship power - equity in shared decision making - we found improvements only in the gender-separate MHC/WHC intervention arm. In the other two arms, the mean shared decision-making score decreased significantly $(P=0.01)$. In examining individual components of this scale, in general across all study arms, women had more say about when the partners discussed serious topics, yet the men had higher levels of power and control in the relationship overall. In linear regression analysis, women in the CHC arm reported a decrease of 1.46 units in the shared decisionmaking score compared with women in the $\mathrm{MHC} / \mathrm{WHC}$ arm ( $\beta=-1.46,95 \% \mathrm{CI}:-2.42,-0.5, P=0.003$ ) (Table 3 ), reflecting less relationship power. For this outcome, then, the MHC/WHC arm appeared to promote shared decision making in relationships more effectively than the $\mathrm{CHC}$ arm.

\section{Relationship communication regarding HIV risk}

At baseline, women reported having communicated recently with their partner on an average of 4.5 of eleven topics related to HIV prevention (Table 2). Across all three intervention arms, there were no significant changes in the number of HIV prevention topics discussed with partners from baseline to 6-months follow-up. Regression analyses also revealed no significant differences between the intervention arms in the number of topics discussed within relationships.

\section{Gender norms}

Perceptions regarding gender norms supporting female autonomy in relationships showed nonsignificant increases among women in the $\mathrm{CHC}$ and $\mathrm{MHC} / \mathrm{WHC}$ arms, alongside a decrease among women in the WHC arm $(P=0.09)$ from baseline to follow-up. In linear regression analysis (Table 3), the CHC intervention was more likely to promote improvement in gender norms supporting female autonomy compared with the WHC intervention $(\beta=0.99,95 \% \mathrm{CI}$ : $0.07,1.91, P=0.035$ ).

\section{Relationship conflict}

At baseline, two-thirds (69.8\%) of participants reported that they had not experienced partner victimization in the previous 6 months across ten types of victimization assessed. At follow-up, $56 \%$ of participants reported no change in whether they had experienced victimization, $27 \%$ who experienced at 


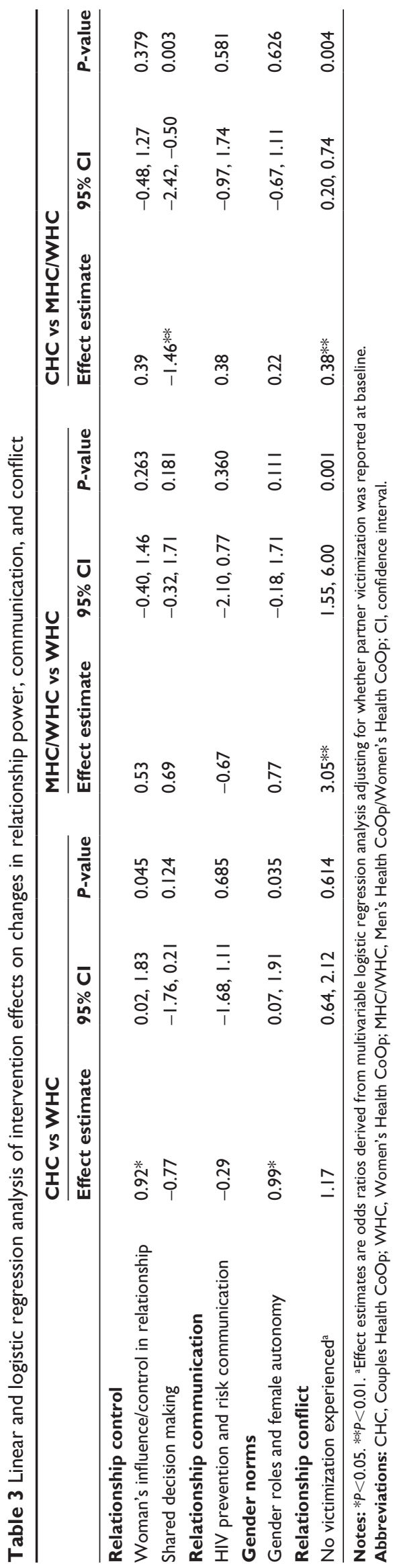

least one form during the 6 months prior to baseline reported experiencing no victimization during the follow-up period, and $17 \%$ experienced victimization during the follow-up period who did not report experiencing any during the 6 months prior to baseline $(P=0.12)$. At follow-up, the proportion of women reporting no partner victimization varied significantly by intervention arm (Table 2): $78.6 \%$ of women in the $\mathrm{MHC} /$ WHC arm, compared with approximately $60 \%$ of women in the other two arms, reported no partner victimization $(P=0.008)$. In logistic regression analysis (Table 3), women in the $\mathrm{MHC} /$ WHC arm had a higher odds of reporting having experienced no victimization during the follow-up period, compared with women in each of the other study arms (odds ratio [MHC/WHC vs $\mathrm{WHC}]=3.05,95 \% \mathrm{CI}: 1.55,6.0, P=0.001$; odds ratio $[\mathrm{CHC}$ vs $\mathrm{MHC} / \mathrm{WHC}]=0.38,95 \% \mathrm{CI}: 0.20,0.74, P=0.004$ ).

\section{Discussion}

Globally, there is a call to address gender-based power in relationships and to achieve greater gender equity and the empowerment of women ${ }^{33}$ as a strategy to confront the structural and contextual drivers of women's continued risk for HIV. ${ }^{34}$ Gender transformative interventions that aim to change gender roles leading to more egalitarian and respectful relationships have shown promise in improving relationship equality and multiple health outcomes for women. ${ }^{35}$ This examination of two models for engaging couples from a highly patriarchal society in group-based HIV prevention that directly addresses gendered norms around sex and roles in relationships, gender equality, and relationship communication highlights that modest shifts in relationship power can be achieved through a two-session intervention and sustained over a 6-month time period. We found that engaging male partners in behavioral interventions for HIV led to modest improvements in the balance of relationship power, as reported by their female partners across multiple measures; however, the aspects of relationship power that improved varied between the couples and gender-separate conditions. Among women in the CHC, measures of female empowerment improved, relative to women in the WHC, including increased relationship control and adoption of fewer traditional and subservient gender norms. In contrast, we found the most substantial improvements in relationship equity and reductions in experiences of partner victimization with an intervention model that engaged women separately from their male partners rather than directly as a couple. Specifically, women in the $\mathrm{MHC} /$ WHC arm reported increases in relationship equity (related to shared decision making), relative to those in the $\mathrm{CHC}$ 
arm, and they reported a higher odds of not experiencing partner victimization relative to the women in each of the other arms. These important findings highlight the need for further attention to the development of both gender-separate and couples interventions. Furthermore, combining these two approaches into a single, extended intervention could yield broader benefits for couples.

The finding that the level of shared decision making decreased in two of the three intervention arms from baseline to follow-up is unexpected. However, in both of these intervention arms, women's understanding and awareness of what constitutes gender inequality and inequity in relationships are likely to have increased as a result of the intervention that they received, prompting increased reporting of inequalities in their relationships. Furthermore, for the WHC intervention arm, male partners did not participate in an intervention promoting gender equality, and therefore, we would not expect to see any positive improvements in perceptions of gendered norms in relationships for women assigned to this condition. That shared decision making nonetheless increased in the gender-separate condition may underscore that a model of engaging men and women separately proved more effective in addressing gender equity in decision making in this population. Men assigned to this condition may have felt freer to talk openly about what was culturally expected of them as men and how change was needed without their female partners being present.

Relationship communication regarding HIV prevention and risk did not improve significantly in any of the three study arms, despite the modest increases observed. Though the interventions aimed to achieve increases in HIV prevention discussions by couples, many couples in fact lacked basic relationship communication skills and did not discuss sex with one another. Thus, communication training included exercises on how to express what members of the couple valued in one another and speaker/listener strategies. Strengthening communication between couples was a necessary first step before communication regarding HIV prevention could be improved. In this population, more sustained opportunities to practice communication strategies are likely needed to achieve more substantial and significant increases; this could be an area for further consideration in ongoing implementation and evaluation of these interventions. Furthermore, more in-depth assessments of the context in which communication about relationships and HIV prevention and risk took place and the quality of these conversations could have been informative to understanding in what ways the intervention influenced partner communication.
Several limitations should be noted. In considering the generalizability of these findings, it is important to remember that this study targeted couples in stable relationships for at least 1 year who resided in a large, high-density South African township with persistently high rates of HIV. Second, the level of reporting of partner victimization, particularly physical and sexual abuse, was low relative to estimates from other studies of partner victimization in South Africa. ${ }^{1,36}$ Couples willing to enroll in an intervention trial may have been reluctant to report victimization; alternatively, those couples who were living in severely abusive relationships may have been unwilling to participate in the study. The overall low levels precluded examination of the effects of the intervention on different types of IPV. Third, we measured outcomes at 6 months only; whether the intervention effects would be sustained over a longer time is not known. Finally, though we did find significant intervention effects between baseline and follow-up for four of the five measures, the changes were relatively modest, and it remains unknown how they might translate, ultimately, to sustained reductions in HIV risk. An extended intervention with more sessions to help reinforce and practice newly learned skills may ultimately produce greater changes.

\section{Conclusion}

Inequalities in gender-based power contribute to the disproportionate burden of HIV among women in South Africa. Both men and women are affected by social constructions of gender, and it remains important to identify interventions that achieve more equity in relationships. ${ }^{12}$ The two models of couple's engagement evaluated in this study highlight a role for both gender-separate conditions promoting male engagement and joint couples, intervention approaches in addressing gender-based inequities in settings where women remain at high risk of HIV infection.

\section{Acknowledgment}

This research was supported by the National Institutes of Health, National Institute on Alcohol Abuse and Alcoholism grant R01 AA018076.

\section{Disclosure}

The authors report no conflicts of interest in this work.

\section{References}

1. Jewkes R, Sikweyiya Y, Morrell R, Dunkle K. The relationship between intimate partner violence, rape and HIV amongst South African men: a cross-sectional study. PLoS One. 2011;6(9):e24256.

2. Coovadia H, Jewkes R, Barron P, Sanders D, McIntyre D. The health and health system of South Africa: historical roots of current public health challenges. Lancet. 2009;374(9692):817-834. 
3. Wechsberg WM, Myers B, Reed E, Carney T, Emanuel AN, Browne FA. Substance use, gender inequity, violence and sexual risk among couples in Cape Town. Cult Health Sex. 2013;15(10):1221-1236.

4. Jewkes R, Abrahams N. The epidemiology of rape and sexual coercion in South Africa: an overview. Soc Sci Med. 2002;55(7):1231-1244.

5. Reed E, Myers B, Novak SP, Browne FA, Wechsberg WM. Experiences of violence and association with decreased drug abstinence among women in Cape Town, South Africa. AIDS Behav. 2014;19(1): 192-198.

6. Watt MH, Sikkema KJ, Abler L, et al. Experiences of forced sex among female patrons of alcohol-serving venues in a South African Township. J Interpers Violence. 2015;30(9):1533-1552.

7. Kim JC, Watts CH, Hargreaves JR, et al. Understanding the impact of a microfinance-based intervention on women's empowerment and the reduction of intimate partner violence in South Africa. Am J Public Health. 2007;97(10):1794-1802.

8. Dworkin SL, Hatcher AM, Colvin C, Peacock D. Impact of a gendertransformative HIV and antiviolence program on gender ideologies and masculinities in two rural, South African communities. Men Masc 2013;16(2):181-202.

9. Jewkes R, Nduna M, Levin J, et al. Impact of stepping stones on incidence of HIV and HSV-2 and sexual behaviour in rural South Africa cluster randomised controlled trial. BMJ. 2008:337:a506.

10. Baird SJ, Garfein RS, McIntosh CT, Ozler B. Effect of a cash transfer programme for schooling on prevalence of HIV and herpes simplex type 2 in Malawi: a cluster randomised trial. Lancet. 2012;379(9823): $1320-1329$.

11. Heise L, Lutz B, Ranganathan M, Watts C. Cash transfers for HIV prevention: considering their potential. J Int AIDS Soc. 2013;16(1):18615.

12. Dayton R, Lanham M, Wilcher R. Engaging Male Partners in Women's Microbicide Use. Durham, NC: FHI 360; 2014.

13. Stadler J, Delany-Moretlwe S, Palanee T, Rees H. Hidden harms: women's narratives of intimate partner violence in a microbicide trial, South Africa. Soc Sci Med. 2014;110:49-55.

14. Montgomery ET, Chidanyika A, Chipato T, van der Straten A. Sharing the trousers: gender roles and relationships in an HIV-prevention trial in Zimbabwe. Cult Health Sex. 2012;14(7):795-810.

15. Kacanek D, Bostrom A, Montgomery ET, et al. Intimate partner violence and condom and diaphragm nonadherence among women in an HIV prevention trial in southern Africa. J Acquir Immune Defic Syndr. 2013;64(4):400-408.

16. Hatcher AM, Colvin CJ, Ndlovu N, Dworkin SL. Intimate partner violence among rural South African men: alcohol use, sexual decisionmaking, and partner communication. Cult Health Sex. 2014;16:1-17.

17. Peacock D, Levack A. The men as partners program in South Africa: reaching men to end gender-based violence and promote sexual and reproductive health. Int J Mens Health. 2004;3(3):173-188.

18. Wechsberg W, Zule W, Minnis A, et al. Couples can change the cultural dynamic of risk after an HIV couples intervention: biobehavioral outcomes from a randomized clustered design in a Cape Town Township. In: AIDS 2014, the 20th International AIDS Conference; 2014; Melbourne, Australia.

19. El-Bassel N, Gilbert L, Wu E, et al. Couple-based HIV prevention for lowincome drug users from New York City: a randomized controlled trial to reduce dual risks. J Acquir Immune Defic Syndr. 2011;58(2):198-206.
20. Wechsberg WM, Jewkes R, Novak SP, et al. A brief intervention for drug use, sexual risk behaviours and violence prevention with vulnerable women in South Africa: a randomised trial of the Women's Health CoOp. BMJ Open. 2013;3(5):e002622.

21. Wechsberg WM, Doherty IA, Myers B, et al. Contextualizing gender differences and methamphetamine use with HIV prevalence within a South African community. Int J Drug Policy. 2014;25(3):583-590.

22. Wechsberg WM, Luseno WK, Kline TL, Browne FA, Zule WA. Preliminary findings of an adapted evidence-based woman-focused HIV intervention on condom use and negotiation among at-risk women in Pretoria, South Africa. J Prev Interv Community. 2010;38(2):132-146.

23. Wechsberg W. Effectiveness of HIV risk reduction initiatives among out-of-treatment non-injection drug users. J Psychoactive Drugs. 1998; 30(3):279-290.

24. Wechsberg WM, Browne FA, Ellerson RM, Zule WA. Adapting the evidence-based Women's CoOp intervention to prevent human immunodeficiency virus infection in North Carolina and international settings. N C Med J. 2010;71(5):477-481.

25. Men As Partners. A Program for Supplementing the Training of Life Skills Educators. New York, USA: Engender Health Planned Parenthood Association of South Africa; 2001.

26. El-Bassel N, Gilbert L, Terlikbayeva A, et al. Effects of a couple-based intervention to reduce risks for $\mathrm{HIV}, \mathrm{HCV}$, and STIs among druginvolved heterosexual couples in Kazakhstan: a randomized controlled trial. J Acquir Immune Defic Syndr. 2014;67(2):196-203.

27. El-Bassel N, Jemmott JB, Landis JR, et al. National Institute of Mental Health Multisite Eban HIV/STD prevention intervention for African American HIV serodiscordant couples: a cluster randomized trial. Arch Intern Med. 2010;170(17):1594-1601.

28. Pulerwitz J, Gortmaker SL, De Jong W. Measuring sexual relationship power in HIV/STD research. Sex Roles. 2000;42(7/8):637-660.

29. Wingood G, DiClemente R. The influence of psychosocial factors, alcohol, drug use on African-American women's high-risk sexual behavior. Am J Prev Med. 1998;15(1):54-59.

30. Sherman SG, Gielen AC, McDonnell KA. Power and attitudes in relationships (PAIR) among a sample of low-income, AfricanAmerican women: implications for HIV/AIDS prevention. Sex Roles. 2000;42:283-294.

31. World Health Organization. WHOMulti-Country Study on Women's Health and Domestic Violence: Core Questionnaire and WHO Instrument Version 9. Geneva, Switzerland: World Health Organization; 2000.

32. Wechsberg WM, Doherty IA, Myers B, et al. Contextualizing gender differences and methamphetamine use with HIV prevalence within a South African community. Int J Drug Policy. 2013;25(3):583-590.

33. Gates M. Putting women and girls at the center of development. Science. 2014;345(6202):1273-1275

34. Klugman J, Hanmer L, Twigg S, Hasan T, McCleary-Sills J, Santamaria J. Voice and Agency: Empowering Women and Girls for Shared Prosperity. Washington, DC: World Bank Group; 2014.

35. Dworkin SL, Treves-Kagan S, Lippman SA. Gender-transformative interventions to reduce HIV risks and violence with heterosexually-active men: a review of the global evidence. AIDS Behav. 2013;17(9):2845-2863.

36. Kalichman SC, Simbayi LC, Cloete A, et al. Integrated gender-based violence and HIV Risk reduction intervention for South African men: results of a quasi-experimental field trial. Prev Sci. 2009;10(3):260-269.

International Journal of Women's Health

\section{Publish your work in this journal}

The International Journal of Women's Health is an international, peerreviewed open-access journal publishing original research, reports, editorials, reviews and commentaries on all aspects of women's healthcare including gynecology, obstetrics, and breast cancer. The manuscript management system is completely online and includes

a very quick and fair peer-review system, which is all easy to use. Visit http://www.dovepress.com/testimonials.php to read real quotes from published authors. 